\title{
Value-Based Segmentation of U.S. Luxury Consumers: Conceptual Replication and Model Validation
}

\author{
Sonali Diddi ${ }^{1} \&$ Srikant Manchiraju ${ }^{2}$ \\ ${ }^{1}$ Department of Design \& Merchandising, Colorado State University, Fort Collins, USA \\ ${ }^{2}$ The Jim Moran School, Florida State University, Tallahassee, USA \\ Correspondence: Sonali Diddi, 1574 Campus Delivery, Department of Design \& Merchandising, Colorado State \\ University, Fort Collins, Colorado, 80523, USA. Tel: 1-970-491-6715.
}

Received: September 8, 2018

Accepted: October 9, 2018 Online Published: November 24, 2018

doi:10.5539/ijms.v10n4p26

URL: https://doi.org/10.5539/ijms.v10n4p26

\begin{abstract}
The primary objective of this study was to understand the U.S. consumers' luxury value perceptions using Luxury Value Perception (LVP) model (Wiedmann, Hennigs \& Siebel, 2009). The study replicated the procedure used in Wiedmann et al.'s (2009) article to validate the dimensions of the LVP model in the U.S. context. Data were collected using an online survey through Amazon Mechanical Turk. The findings revealed the applicability of the LVP model in the U.S. context and revealed interesting differences in luxury value perceptions among U.S. and German consumers. This study advances theory as it is the first to validate the latent luxury value construct as influenced by individual, social and functional luxury value perceptions in the U.S. context. The LVP model helped identify luxury value drivers of U.S. consumers and cluster them in homogenous segments. These findings may potentially help U.S. luxury brand marketers to know the needs and values of different customer segments, ultimately helping them to develop effective brand positioning strategies in a competitive marketplace.
\end{abstract}

Keywords: consumption, luxury, Luxury Value Perception model, market segmentation, values

\section{Introduction}

The luxury market continues to grow substantially worldwide. According to Deloitte's Global Powers of Luxury Goods report (2017), the global luxury market was worth US\$212 billion in 2015 with an average luxury goods sales of top 100 companies equaling to $\$ 2.1$ billion. Globally, the luxury market grew by $5 \%$ to an estimated $\$ 1.5$ trillion in 2017 (Bain, 2017). Though the U.S. is leading sales - approximately $\$ 85$ billion in the global luxury market, it experienced a slow growth in 2016. Industry experts predict the U.S. luxury goods market to increase by a further US $\$ 18.5$ billion by 2021 (Danzinger, 2017; Roberts, 2017). In sum, luxury consumption is on the rise and is more dynamic today than previous decades. Marketers have realized the importance of understanding the new luxury consumer, and will need to accommodate digital savvy consumers who increasingly lead on-the-go lifestyles.

Previous research focused on issues such as luxury consumption as a social strategy (Nelissen \& Meijers, 2011), attitudes toward luxury (Dubois \& Laurent, 1994), the luxury wine trade (Reyneke, Pitt, \& Berthon, 2011), happiness and luxury consumption (Hudders \& Pandelaere, 2012), status signaling with luxury goods (Han, Nunes, \& Drèze, 2010), self-congruity and luxury brands (Liu, Li, Mizerski, \& Soh, 2012), counterfeit luxury brands (Wilcox, Kim, \& Sen, 2009), and attitudes towards luxury restaurants (Lee \& Hwang, 2011). Although the existing studies related to luxury consumption are helpful, they contribute little toward our understanding of luxury products' marketing and monitoring in the fast changing retail environment (Vigneron \& Johnson, 1999, 2004; Wiedmann et al., 2009). Given the projected growth of the U.S. luxury market and changing consumer demographics and psychographics, it is imperative that luxury scholars and marketers understand consumers' motivations to buy luxury.

Wiedmann et al.'s (2009) study was one of the earliest studies to explore consumers' luxury value perceptions. They developed a multidimensional concept of luxury value perceptions that encompassed financial, functional, individual and social components to identify different types of luxury consumers. To the researchers knowledge, very little has been examined from consumers' luxury value perceptions especially after the 2008 global recession. Luxury retail has also evolved exponentially in the past decade with online luxury offerngs, diffusion 
lines for different consumer segments warranting further study of how consumers' value their luxury goods and services. The purpose of this study was to replicate Wiedmann et al.'s (2009) study to confirm the dimensionality of the constructs proposed in the Luxury Value Perceptions (LVP) model in the U.S. context. Existing literature suggests that replication studies are imperative to establish external validity of frameworks or concepts developed (MacDonald \& Sharp 2000). Limited research has explored the market segmentation of U.S. luxury consumers based on luxury value perceptions (Hennings et al. 2012). Bain \& Company (2017) also predicted that the U.S. demographic shift will entail an increase in luxury sales. However, luxury brands are out of touch with the evolving mindsets of the US luxury market, which might lead to decrement in luxury sales. Hence, another important aspect of the present study was to further understand and segment the U.S. luxury market.

\section{Literature Review and Hypotheses Development}

Vigneron and Johnson (1999) point to the use of models of conspicuous consumption (Mason, 1981), the materialism model (Belk, 1985; Richins \& Dawson, 1992), and models of involvement (Horiuchi, 1984) to understand luxury consumption. It has been maintained that these models fail to capture the complexity of luxury consumption (Hennigs et al., 2012; Vigneron \& Johnson, 1999). For example, according to the conspicuous consumption perspective, consumers are motivated to engage in luxury consumption "to impress others" (Hennigs et al., 2012, p. 1019). However, Vigneron and Johnson (1999) maintained that luxury consumption entails several physical and psychological benefits beyond social benefits. Furthermore, some luxury scholars questioned the applicability of traditional marketing strategies in the context of luxury consumption (Kapferer \& Bastien, 2008). Therefore, luxury scholars and strategists have developed various frameworks and models related to luxury consumption (Shukla \& Purani, 2012; Tynan, Mckechnie, \& Chhuon, 2010; Vigneron \& Johnson, 2004). Of particular interest for the present study is Vigneron and Johnson's (2004) brand luxury index framework (BLI), that contained personal motives, such as perceived hedonic pleasure and extended sense of self, and non-personal motives like perceived quality of the product or service and conspicuousness, which determined an individual's propensity toward luxury consumption. Wiedmann, Hennigs, and Siebels (2007) extended the brand luxury framework using Bourdieu's capital theory (1986), which they labeled the determinants of consumers' luxury value perceptions (LVP) model.

The LVP model conceptualized that consumers' luxury value perception is determined by four factors, namely financial, functional, individual, and social value dimensions (Hennigs et al., 2012; Wiedmann et al., 2007, 2009), however, Wiedmann et al.'s (2009) study found that that only three out of the four factors - functional, individual, and social values contributed to consumers' luxury value perceptions. This finding was also consistent with the BLI framework (Vigneron \& Johnson, 2004). Some assumptions related to the LVP model include, luxury being considered subjective, a multi-dimensional construct. Second, a luxury brand is defined as the highest level of prestige brands, entailing physical, psychological, and social values (or benefits). Third, consistent with the value definition, consumer luxury value (or perception) refers to consumers' beliefs about luxury consumption leading to desirable ends. Finally, consumer luxury value is a function of various motives (e.g., functional, social), which may manifest as luxury consumption behavior.

In the present study, Wiedmann et al.'s (2009) LVP model was employed to understand luxury consumption behavior in the U.S. A subsequent study using the LVP model was done by Hennings et al. (2012), to examine value perceptions of luxury in different cultural contexts, including the U.S. Hennings et al.'s (2012) study used a shortened version of the LVP scale. Both Wiedmann et al. (2009) and Hennigs et al.'s (2012) studies conducted exploratory techniques to develop dimensions and factor structures. Furthermore, Hennings et al. (2012) used a shortened version of the original LVP scale. It is imperative that robust statistical techniques are used to confirm dimensions and factor structures of the LVP scale. This will help in validating and extending the applicability of factors identified in the LVP model. The present study addresses the Wiedmann et al.'s (2009) call to confirm the dimensions of in the LVP model (financial, functional, individual and social) using confirmatory factor analysis.

\subsection{Financial Value}

The financial dimension of luxury value refers to monetary aspects such as price, resale, or investment. It also represents what is given up or sacrificed to obtain a luxury product or service. In fact, several scholars have noted that one of the hallmarks of a luxury brand is its price (Kapferer \& Bastien, 2008; Vigneron \& Johnson, 1999). Likewise, Dubois et al. (2001), in a qualitative study related to consumer's perception of luxury, found six dimensions of luxury, one of which was high price. Kardes, Posavac, Cronley, and Herr (2008) noted the implicit theories of price-quality inference, which refers to consumers' implicit assumption that product quality is positively and strongly correlated with price. Similarly, Groth and McDaniel (1993) proposed the concept of "an exclusive value principle," which proposes that consumers who seek unique products are likely to use price cues 
as representative of uniqueness and prestige. Thomas (2008) mentioned that, in the context of luxury consumption, the higher the financial sacrifice, the higher the value associated with the target luxury brand. Consequently, the following hypothesis is proposed:

H1: The consumer's perceived financial value of luxury brand/service is an appropriate criterion for value-based segmentation of the U.S. luxury consumer.

\subsection{Functional Value}

The functional dimension of luxury value refers to the luxury product's or service's benefits, which include perceived quality, usability, and uniqueness (Wiedmann et al., 2009). Shukla and Purani (2012) used the term "utilitarian" value as a synonym, which refers to rational purposes related to luxury product or service consumption. Perceived usability refers to a product's or service's performance and whether it satisfies one's needs (Wiedmann et al., 2009). Lim, Ting, Khoo, and Wong (2012) found that consumers seek luxury products because of their long-lasting usage. Perceived quality refers to a "consumer's judgment about a product's overall excellence or superiority" (Tsiotsou, 2006, p. 210). Vigneron and Johnson (1999) refer to perceived quality value as "the perfectionism effect," for perfectionist consumers who depend on their own perception of the product's quality. Perceived uniqueness of a product refers to the degree to which the consumer regards a luxury product as different from other products in the same category (Tian, Bearden, \& Hunter, 2001). Wiedmann et al. (2009) noted that uniqueness is associated with perceived exclusivity and rarity of the luxury product. The uniqueness offered by the product is used to define oneself and achieve superior societal standing (Franke \& Schreier, 2008; Lim et al., 2012). Therefore, based on the literature reviewed, the following hypothesis is proposed:

H2: The consumer's perceived functional value of luxury brand/service is an appropriate criterion for value-based segmentation of the U.S. luxury consumer.

\subsection{Individual Value}

The individual dimension of luxury value refers to personal orientation toward luxury consumption, and it consists of three antecedents: perceived materialistic value, perceived hedonic value, and perceived self-identity value. Perceived self-identity value focuses on an individual's internal, or private, aspect of self-perception (Wiedmann et al., 2009). Vigneron and Johnson (2004) noted that luxury purchases entail symbolic meaning that is used to develop or maintain one's self-identity. Perceived hedonic value stems from hedonic consumption and is defined as "those facets of consumer behavior that relate to the multisensory, fantasy, and emotive aspects of one's experience with products" (Hirschman \& Holbrook, 1982, p. 92). Lim et al., (2012) found that consumers engaging in luxury consumption experience hedonic pleasure. Perceived materialistic value has its roots in materialism defined as a "set of centrally held beliefs about the importance of possessions in one's life" (Richins \& Dawson, 1992, p. 308). In recent studies, Hudders and Pandelaere (2012) and Kalyoncuoglu and Sahin (2017) found that materialism was positively associated with luxury consumption as materialists acquire possessions to conspicuously display them, and they equate luxury consumption with personal happiness. Based on the literature reviewed, the following hypothesis is proposed:

H3: The consumer's perceived individual value of luxury brand/service is an appropriate criterion for value-based segmentation of the U.S. luxury consumer.

\subsection{Social Value}

Luxury consumption's role is to create social stratification (Kapferer \& Bastien, 2008). Luxury consumption confers social value by creating a favorable social image and societal recognition (Lim et al., 2012). Furthermore, luxury products serve as social and symbolic markers of group membership (Kapferer \& Bastien, 2008; Vigneron \& Johnson, 1999). According to the LVP model, social value has two antecedents, perceived conspicuous consumption and perceived prestige value in social networks. Perceived conspicuousness value, in other words conspicuous consumption, refers to the act of spending one's money on frivolous and wasteful goods to gain status and impress others (Griskevicius et al., 2007). Nelissen and Meijers (2011) explored the social benefits of luxury consumption and found that luxury consumption was a profitable social strategy, which elicited beneficial treatment from others toward individuals engaging in luxury consumption. Perceived prestige value in social networks refers to consumers who engage in luxury consumption for group affiliation (Vigneron \& Johnson, 1999). Consequently, this influences individuals to conform to affluent lifestyles and/or distinguish themselves from non-affluent lifestyles (Han, Nunes, \& Drèze, 2010; Wiedmann et al., 2007). Therefore, in the case of perceived prestige value, social referencing plays an important role in predicting an individual's tendency toward luxury consumption (Wiedmann et al., 2007; Vigneron \& Johnson, 1999). Therefore, based on the literature reviewed, the following hypothesis is proposed: 
H4: The consumer's perceived social value of luxury brand/service is an appropriate criterion for value-based segmentation of the US luxury consumer.

\section{Method}

\subsection{Instrument Development}

As this study was a replication of Wiedmann et al.'s (2009) study, it used items from their original study. The survey instrument consisted of statements that measured each luxury dimensions in detail. The survey also included questions related to demographic characteristics. The survey had a screening question that asked participants if they purchased a luxury product in the past six months. Only if the participants answered a "yes", they were directed to the rest of questions. Based on the assumptions of luxury per Wiedmann et al. (2009) study, participants were left to determine the concept of luxury due its subjective nature. For instance, plasma TV might be a luxury product for someone, but a necessity for someone else. All survey items were rated on a 7-point Likert scale ( $1=$ Strongly Disagree, 7 = Strongly Agree).

\subsection{Sampling Procedure}

An online survey was created using Qualtrics survey platform and data was collected using Amazon Mechanical Turk. This method of data collection has shown to provide high-quality data that is reliable and used in marketing studies (Buhrmester, Kwang, \& Gosling, 2011). The sample consisted of both male and female consumers ages 18 and above from the U.S.

\subsection{Demographic Profile}

A total of 345 participants took part in the survey; however, only 232 consumers completed the survey successfully. The largest (40.95\%) age group were participants aged 31-45 years old, followed by the group of 18-30 years old that accounted for $37.93 \%$ of the sample; and $18.97 \%$ of the participants were in the age range of 46-60 years old. The smallest group accounted for $2.16 \%$ of the sample whose age was between $62-75$ years old. Majority of the participants were educated with at least 39.7\% of them having a bachelor's degree, $34.5 \%$ had master's degree followed by $10.8 \%$ having doctoral degrees. More than half of the sample $(54.3 \%)$ had an annual income between $\$ 40,000-\$ 50,000$, about $35 \%$ had income between $\$ 50,000$ to $\$ 65,000$ and about $11 \%$ had their income above $\$ 65,000$. Majority of the participants were Caucasian $(81 \%)$, followed by Hispanic or Latino (19\%). Other ethnicities included African-American, Mixed/Bi-racial, and Native American.

\section{Results}

Data analyses involved exploratory and confirmatory factor analyses, followed by cluster analysis and discriminant analysis. For testing the hypotheses, IBM SPSS 25 and Mplus7 were used to analyze the data. Exploratory factor analysis (EFA) using principal component analysis (PCA) with Varimax rotation was conducted to identify the underlying dimensions and factor structures. This method ensured maximum dispersion of loadings within factors. Varimax rotation was used as in this type of rotation factors are independent. EFA produced ten-factor structure with a Kaiser-Meyer-Olkin (KMO) measure of 0.90 that summarized 48 items with medium ( $>0.6)$ to high (0.9) factor loadings. Bartlett's test of sphericity, was also significant. However, some items were either crossloading or had factor loading less than the minimum threshold level of 0.5 and were not considered in further analyses. Items loading above .50 on one factor and with a minimum difference of .30 on all other factors were retained (George \& Mallery, 2007). EFA yielded a three-factor model for the Functional Value dimension; six-factor model for Individual Value dimension and one-factor model for Social Value dimension. These results were consistent with Wiedmann et al.'s (2009) factor structure. Table 1 provides factor loadings from EFA. 
Table 1. Exploratory factor analysis results of luxury value dimensions

\begin{tabular}{|c|c|c|}
\hline $\begin{array}{l}\text { Variable } \\
\text { Name }\end{array}$ & Items & $\begin{array}{l}\text { Factor } \\
\text { Loading }\end{array}$ \\
\hline FVD & Functional Value Dimension & \\
\hline$F V$ & Factor 2: Usability Value & \\
\hline FV1 & In my opinion, luxury is really useless ${ }^{\mathrm{R}}$ & 0.624 \\
\hline FV2 & *In my opinion, luxury is just swanky. ${ }^{\mathrm{R}}$ & 0.156 \\
\hline FV3 & In my opinion, luxury is pleasant. & 0.689 \\
\hline FV4 & *In my opinion, luxury is old-fashioned. ${ }^{\mathrm{R}}$ & 0.209 \\
\hline FV6 & Luxury products make life more beautiful. & 0.680 \\
\hline FV7 & I am not interested in luxury. ${ }^{\mathrm{R}}$ & 0.663 \\
\hline$U V$ & Factor 3: Uniqueness Value & \\
\hline UV1 & A luxury product cannot be sold in supermarkets. & 0.789 \\
\hline UV2 & True luxury products cannot be mass-produced. & 0.862 \\
\hline UV3 & Few people own a true luxury product. & 0.815 \\
\hline UV4 & *People who buy luxury products try to differentiate themselves from the others. & 0.405 \\
\hline QV1 & $\begin{array}{l}\text { I'm inclined to evaluate the substantive attributes and performance of a luxury brand myself rather than listen to } \\
\text { others' opinions. }\end{array}$ & 0.712 \\
\hline QV2 & $\begin{array}{l}\text { The luxury brand preferred by many people but that does not meet my quality standards will never enter into my } \\
\text { purchase consideration }\end{array}$ & 0.763 \\
\hline QV3 & *I buy a luxury brand for satisfying my personal needs without any attempt to make an impression on other people. & 0.394 \\
\hline IVD & Individual Value Dimension & \\
\hline SI & Factor 4: Self-Identity Value & \\
\hline SI1 & I never buy a luxury brand inconsistent with the characteristics with which I describe myself & 0.748 \\
\hline $\mathrm{SI} 2$ & The luxury brands I buy must match what and who I really am & 0.719 \\
\hline SI3 & My choice of luxury brands depends on whether they reflect how I see myself but not how others see me. & 0.737 \\
\hline$M V$ & Factor 5: Materialistic Value & \\
\hline MV1 & My life would be better if I owned certain things I don't have. & 0.796 \\
\hline MV2 & I'd be happier if I could afford to buy more things. & 0.817 \\
\hline MV3 & It sometimes bothers me quite a bit that I can't afford to buy all the things I'd like. & 0.726 \\
\hline MV4 & I have all the things I really need to enjoy life. ${ }^{R}$ & 0.720 \\
\hline$H V S G$ & Factor 6: Hedonic Value - Self-Gift Giving & \\
\hline HVSG3 & *When in a bad mood, I may buy luxury brands as self-given gifts for alleviating the emotional burden & 0.487 \\
\hline HVSG4 & $\begin{array}{l}\text { Reward for hard work or that I feel I have earned or am entitled to is an important motivator for my luxury } \\
\text { consumption. }\end{array}$ & 0.774 \\
\hline HVSG5 & *To me, luxury consumption is a way to reduce stress. ${ }^{\mathrm{R}}$ & 0.447 \\
\hline$H V E X$ & Factor 7: Hedonic Value - Extravagance & \\
\hline HVEX1 & I enjoy spending money on things that aren't practical. & 0.614 \\
\hline HVEX2 & I usually buy only the things I need. ${ }^{\mathrm{R}}$ & 0.819 \\
\hline HVEX3 & *Buying things gives me a lot of pleasure. & 0.381 \\
\hline$H V S D$ & Factor 8: Hedonic Value - Self Directed Pleasure & \\
\hline HVSD1 & Luxury brands are one of the sources for my own pleasure without regard to the feelings of others. & 0.518 \\
\hline HVSD2 & I can enjoy luxury brands entirely on my own terms no matter what others may feel about them. & 0.586 \\
\hline HVLE & Factor 9: Hedonic Value - Life Enrichment & \\
\hline HVLE1 & For me as a luxury consumer, cultural development is an important motivator. & 0.692 \\
\hline HVLE2 & Purchasing luxury brands provides deeper meaning in my life. & 0.683 \\
\hline HVLE3 & Self-actualization is an important motivator for my luxury consumption & 0.777 \\
\hline HVLE4 & *Luxury consumption enhances the quality of my life. & 0.428 \\
\hline SVD & Social Value Dimension & \\
\hline$S V$ & Factor 10: Prestige Value in Social Networks & \\
\hline SV1 & I like to know what brands and products make good impressions on others. & 0.779 \\
\hline SV2 & I usually keep up with style changes by watching what others buy & 0.766 \\
\hline SV3 & $\begin{array}{l}\text { Before purchasing a product it is important to know what brands or products to buy to make good impressions on } \\
\text { others. }\end{array}$ & 0.868 \\
\hline SV4 & Before purchasing a product it is important to know what kinds of people buy certain brands or products. & 0.876 \\
\hline SV5 & Before purchasing a product it is important to know what others think of people who use certain brands or products. & 0.868 \\
\hline SV6 & I tend to pay attention to what others are buying. & 0.611 \\
\hline SV7 & Before purchasing a product it is important to know what my friends think of different brands or products. & 0.735 \\
\hline SV8 & I actively avoid using products that are not in style. & 0.738 \\
\hline SV9 & *If I were to buy something expensive, I would worry about what others would think of me & 0.483 \\
\hline SV10 & Social standing is an important motivator for my luxury consumption & 0.805 \\
\hline SV11 & *For me as a luxury consumer, sharing with friends is an important motivator. & 0.404 \\
\hline SV12 & I often consult my friends to help choose the best alternative available from a product category. & 0.712 \\
\hline
\end{tabular}

${ }^{\mathrm{R}}$ Reverse coded *Factor loading $<0.5$, not included in further analyses 
Based on the EFA results, Confirmatory factor analysis (CFA) was conducted to confirm the factor structure. CFA allows testing the relationship between observed variables and their underlying latent construct (Thompson, 2004). The model fit indices $(\chi 2=1093.246, \mathrm{df}=581, p$-value $<0.001, \mathrm{CFI}=0.92, \mathrm{TLI}=0.91$, RMSEA $=0.06$, SRMR $=0.05)$ provided an acceptable model fit $(\mathrm{Hu} \&$ Bentler, 1999) and all measures were within acceptable-to-good fit ranges. Table 2 provides standardized factor loadings, Average Variance Extracted (AVE) and composite reliability. The high item-factor loadings for each factor provide further evidence of convergent validity. All parameters were statistically significant at the $p<.001$ level. Scales for each of the latent variables exceeded minimum levels of acceptable composite reliability $(>0.70)$. AVE also exceeded the minimum threshold of 0.50. Results of CFA for the full measurement model indicated acceptable fit, reflecting that the model fit the data reasonably well. Reliability was calculated for all the factors and dimensions using Cronbach's alpha that ranged from 0.70 to 0.92 , indicating high internal consistency for the constructs.

Table 2. Confirmatory factor analysis of luxury value dimensions

\begin{tabular}{|c|c|c|c|c|c|c|}
\hline Variable Name & $\beta$ & Std. Error & $t$-value* & Cronbach's $\alpha$ & AVE & Composite Reliability \\
\hline \multicolumn{4}{|c|}{ Functional Value Dimension } & 0.70 & 0.65 & 0.95 \\
\hline \multicolumn{4}{|c|}{ Factor 1: Usability Value } & 0.91 & 0.50 & 0.83 \\
\hline FV1 & 0.788 & 0.028 & 28.053 & & & \\
\hline FV3 & 0.822 & 0.025 & 33.541 & & & \\
\hline FV5 & 0.872 & 0.019 & 45.065 & & & \\
\hline FV6 & 0.843 & 0.022 & 37.748 & & & \\
\hline FV7 & 0.828 & 0.024 & 34.46 & & & \\
\hline \multicolumn{4}{|c|}{ Factor 2: Uniqueness Value } & 0.83 & 0.63 & 0.84 \\
\hline UV1 & 0.708 & 0.04 & 17.499 & & & \\
\hline UV2 & 0.877 & 0.033 & 26.455 & & & \\
\hline UV3 & 0.791 & 0.036 & 21.707 & & & \\
\hline \multicolumn{4}{|c|}{ Factor 3: Quality Value } & 0.70 & 0.56 & 0.71 \\
\hline QV1 & 0.827 & 0.183 & 4.524 & & & \\
\hline QV2 & 0.654 & 0.149 & 4.406 & & & \\
\hline \multicolumn{4}{|c|}{ Individual Value Dimension } & 0.89 & 0.63 & 0.96 \\
\hline \multicolumn{4}{|c|}{ Factor 4: Self Identity Value } & 0.79 & 0.57 & 0.81 \\
\hline SI1 & 0.626 & 0.048 & 13.167 & & & \\
\hline SI2 & 0.947 & 0.04 & 23.928 & & & \\
\hline SI3 & 0.646 & 0.05 & 12.977 & & & \\
\hline \multicolumn{4}{|c|}{ Factor 5: Materialistic Value } & 0.87 & 0.65 & 0.88 \\
\hline MV1 & 0.865 & 0.02 & 44.043 & & & \\
\hline MV2 & 0.964 & 0.013 & 71.842 & & & \\
\hline MV3 & 0.762 & 0.03 & 25.273 & & & \\
\hline MV4 & 0.579 & 0.046 & 12.547 & & & \\
\hline \multicolumn{4}{|c|}{ Factor 6: Hedonic Value - Self Gift-Giving } & 0.88 & 0.71 & 0.88 \\
\hline HVSG1 & 0.813 & 0.027 & 29.78 & & & \\
\hline HVSG2 & 0.863 & 0.023 & 37.247 & & & \\
\hline HVSG4 & 0.857 & 0.024 & 36.242 & & & \\
\hline \multicolumn{4}{|c|}{ Factor 7: Hedonic Value - Extravagance } & 0.66 & 0.58 & 0.72 \\
\hline HVEX1 & 0.94 & 0.081 & 11.672 & & & \\
\hline HVEX2 & 0.524 & 0.065 & 8.026 & & & \\
\hline \multicolumn{4}{|c|}{ Factor 8: Hedonic Value - Self-Directed Pleasure } & 0.77 & 0.63 & 0.78 \\
\hline HVSD1 & 0.822 & 0.033 & 24.944 & & & \\
\hline HVSD2 & 0.769 & 0.036 & 21.555 & & & \\
\hline \multicolumn{4}{|c|}{ Factor 9: Hedonic Value -Life Enrichment } & 0.81 & 0.60 & 0.81 \\
\hline HVLE1 & 0.629 & 0.046 & 13.686 & & & \\
\hline HVLE2 & 0.854 & 0.029 & 29.222 & & & \\
\hline HVLE3 & 0.818 & 0.032 & 25.917 & & & \\
\hline \multicolumn{4}{|c|}{ Social Value Dimension } & 0.94 & 0.62 & 0.94 \\
\hline \multicolumn{4}{|c|}{ Factor 10: Prestige Value in Social Networks } & 0.94 & 0.62 & 0.94 \\
\hline SV1 & 0.789 & 0.027 & 29.293 & & & \\
\hline SV2 & 0.767 & 0.029 & 26.113 & & & \\
\hline SV3 & 0.9 & 0.015 & 60.123 & & & \\
\hline SV4 & 0.89 & 0.016 & 56.122 & & & \\
\hline SV5 & 0.85 & 0.02 & 42.123 & & & \\
\hline SV6 & 0.62 & 0.043 & 14.514 & & & \\
\hline SV7 & 0.747 & 0.031 & 23.7 & & & \\
\hline SV8 & 0.706 & 0.035 & 20.237 & & & \\
\hline SV10 & 0.8 & 0.026 & 30.937 & & & \\
\hline
\end{tabular}

$* \mathrm{p} \leq 0.001$. 
The data was further analyzed using cluster analysis to identify different groups of luxury U.S. consumers based on their luxury value perceptions. Hierarchical (agglomerative) clustering using Ward's method was conducted to determine the number of clusters. This method ensured comparison of individual cases to determine natural relationships between hypothesized relationships. This resulted in four clusters, which is consistent with the LVP model. This was validated using non-hierarchical k-means cluster analysis (Table 3). The results indicated that perceived luxury value variables contributed towards formation of clusters. The US sample revealed that consumers uniqueness value $(F=53.439)$, hedonic value - self-directed pleasure $(F=28.654)$ and self-identity value $(F=24.468)$ had considerable differences, whereas materialistic value did not contribute greatly to differences between the clusters $(F=4.747)$. Discriminant analysis (Table 4$)$ was conducted to check the cluster groupings which showed significant differences between the group characteristics. Overall 99.6 percent of the cases were assigned to their correct group, validating the results of cluster analysis.

\section{Discussion}

The findings of the present study support the hypotheses ( $\mathrm{H} 2, \mathrm{H} 3$, and $\mathrm{H} 4)$ that consumers' perceived functional, individual and social values of luxury brand/service are appropriate criteria for value-based segmentation of the U.S. luxury consumer. Consumers' perceived financial value related to luxury brand/service was not found to be an appropriate criterion for value-based segmentation for the U.S. sample. These results are consistent with Wiedmann et al.'s (2009) original study. Findings from the CFA confirm the factor structures of luxury value dimensions as proposed by Wiedmann et al. (2007, 2009). It is important to note that the some items were not included in the final CFA analysis (refer Table 2). Financial value did not play an important role in determining consumers' perceptions of luxury value in the U.S. context. This could be due to increasing luxury product offerings of affordable diffusion lines by luxury brands (e.g. Armani Exchange by Armani) and the changing consumer demographics in the U.S. luxury market. This result is also consistent with Hennings et al. (2012) cross-cultural study that showed U.S. consumers do not associate luxury brands with financial aspects.

Based on the variables from which they were derived, the four clusters can be described as follows. The functional materialists (Cluster 1) comprised of $12.5 \%$ of the sample, smallest among all the other clusters.

Table 3. Luxury value segments: k-means cluster results

\begin{tabular}{|c|c|c|c|c|c|}
\hline Luxury Value Dimensions & $\begin{array}{l}\text { Functional } \\
\text { Materialsits } \\
(n=29) \\
\end{array}$ & $\begin{array}{l}\text { Self-seeking } \\
\text { Hedonists } \\
(n=106) \\
\end{array}$ & $\begin{array}{l}\text { Rational } \\
\text { Functionalists } \\
(n=40)\end{array}$ & $\begin{array}{l}\text { Introverted } \\
\text { Hedonists } \\
(n=57) \\
\end{array}$ & $F^{\mathrm{a}}$ \\
\hline \multicolumn{6}{|l|}{ Functional Value Dimension } \\
\hline Usability Value & -.34018 & .24624 & .06773 & -.33237 & 5.756 \\
\hline Quality Value & .15051 & -.36548 & .10743 & .52771 & 11.846 \\
\hline Uniqueness Value & -1.38054 & -.18344 & .64247 & .59265 & 53.439 \\
\hline \multicolumn{6}{|l|}{ Individual Value Dimension } \\
\hline Self-Identity Value & -.64842 & .09596 & .87749 & -.46434 & 24.468 \\
\hline Materialistic Value & .22523 & -.22403 & .41171 & .01310 & 4.747 \\
\hline Hedonic Value a - Self-Gift Giving & -.18193 & .30003 & -.19810 & -.32636 & 6.478 \\
\hline Hedonic Value b - Extravagance & -.70890 & .04429 & -.02741 & .29753 & 7.148 \\
\hline Hedonic Value c - Self-Directed Pleasure & -.31009 & .10545 & -.95535 & .63208 & 28.654 \\
\hline Hedonic Value d - Life Enrichment & -.76609 & .45987 & -.17799 & -.34053 & 19.576 \\
\hline \multicolumn{6}{|l|}{ Social Value Dimension } \\
\hline Prestige Value in Social Networks & .04403 & .25289 & -.57047 & -.09236 & 7.338 \\
\hline
\end{tabular}

\footnotetext{
${ }^{\text {a }}$ All reported $F$ values are significant.
} 
Table 4. Discriminant analysis of luxury value factors

\begin{tabular}{|c|c|c|c|c|c|}
\hline $\begin{array}{l}\text { Discriminant } \\
\text { Function }\end{array}$ & Eigenvalue & $\begin{array}{l}\text { Canonical } \\
\text { Correlation }\end{array}$ & Wilk's Lambda & $\chi^{2}$ & Sig. \\
\hline 1 & 1.548 & .779 & .088 & 543.179 & .000 \\
\hline 2 & 1.363 & .759 & .225 & 333.711 & .000 \\
\hline \multirow[t]{2}{*}{3} & .878 & .684 & .533 & 141.128 & .000 \\
\hline & & & Function 1 & Function 2 & Function 3 \\
\hline \multicolumn{6}{|c|}{ Centroids (group means) } \\
\hline Cluster 1 & & & -1.971 & -1.225 & -1.693 \\
\hline Cluster 2 & & & -.590 & .996 & .434 \\
\hline Cluster 3 & & & 2.138 & .556 & -1.161 \\
\hline Cluster 4 & & & .599 & -1.620 & .869 \\
\hline \multicolumn{6}{|c|}{ Significant variable (structure matrix) } \\
\hline Usability Valu & & & -.004 & .233 & .043 \\
\hline Uniqueness $\mathrm{V}$ & & & .608 & -.045 & .381 \\
\hline Quality Value & & & .125 & -.310 & -.016 \\
\hline Self-Identity & & & .292 & .351 & -.157 \\
\hline Materialistic V & & & .107 & -.078 & -.204 \\
\hline \multicolumn{3}{|c|}{ Hedonic Value a - Self-Gift Giving } & -.107 & .213 & .082 \\
\hline \multicolumn{3}{|c|}{ Hedonic Value b - Extravagance } & .134 & .006 & .274 \\
\hline \multicolumn{3}{|c|}{ Hedonic Value c - Self-Directed Pleasure } & -.162 & -.216 & .558 \\
\hline \multicolumn{3}{|c|}{ Hedonic Value d - Life Enrichment } & -.037 & .370 & .279 \\
\hline \multicolumn{3}{|c|}{ Prestige Value in Social Networks } & -.207 & .070 & .163 \\
\hline
\end{tabular}

Note. Classification matrix revealed that $99.6 \%$ of the cases were classified correctly.

Members of this group comprised of $51.7 \%$ female who showed high ratings for materialistic value and quality value, whereas uniqueness and hedonic - life enrichment values were rather unimportant. Their mean ratings for quality value were slightly higher than Clusters 2 and 3. Participants in this cluster felt that owning things would make their lives better. Based on the high ratings of quality value, it was also evident that the participants in this cluster gave importance to the quality of luxury products they owned.

Comprising $45.69 \%$ of the sample, the self-seeking hedonists (Cluster 2) was the largest of all the clusters. The mean scores for hedonic value factors for these cluster members taken as a whole were higher than those recorded by other groups. This cluster comprised of almost half of the sample. It is important to note that the participants in this cluster had highest ratings for life-e.nrichment, self gift-giving and prestige value associated with luxury consumption. In contrast, the participants had lower scores on quality and materialistic values in relation to luxury consumption. The participants in this cluster perceived luxury consumption with higher quality of life and engaged in luxury consumption to satisfy their individual needs and to make them feel good about themselves. Furthermore, participants considered social value as important in their perception of luxury value as evidenced by high scores with prestige value. This also emphasized that participants related luxury to status consumption. Interestingly, participants in this cluster did not relate luxury consumption as being materialistic or of high quality. The rational functionalists (Cluster 3) made up of $17.24 \%$ of the sample. Its members had very high ratings for self-identity value and uniqueness values compared to all other cluster groups. Furthermore, participants in this cluster showed highest ratings for materialistic values than any other cluster. Luxury consumers in this cluster seek exclusive and unique offerings of the luxury brand or service to stand out. Owning luxury products allowed them to enhance their identity. Members $(25.47 \%)$ of the introverted hedonists (Cluster 4) were the second largest cluster and constituted to almost quarter of the sample. Participants in this cluster perceived the hedonic aspects of self-directed pleasure and uniqueness value as important in their perceptions of luxury value. It is important to note that participants in this cluster related luxury value to personal pleasure in owning/experiencing unique and quality luxury product/service offerings versus luxury consumption as a way to fit in the society.

The comparison of results between the present study and the Wiedmann et al.'s (2009) study revealed interesting findings. The U.S. sample perceived luxury primarily from an individual value dimension (e.g. life-enrichment, self identity, self gift-giving, self-directed pleasure), followed by social value dimension (e.g. prestige) and lastly functional value dimension (quality, usability). The focus of "self" was evident in U.S. luxury consumers as all clusters showed higher means for hedonic values and self-identity values. This is consistent with numerous market studies that show the unique characteristics of U.S. millennials (average age of consumers in this study). U.S. millennials when compared to German consumers prioritized individualism and self (Wike, 2016). In the 
current study, almost half of the sample was grouped in self-seeking hedonists whereas the German clusters were more uniform in their cluster groupings and the largest cluster perceived luxury as "prestige value in social networks" in the social value dimension which was was less important to the U.S. luxury consumers. In Wiedmann et al.'s (2009) study, German consumers also emphasized the importance they attached to functional value dimension (specifically usability and quality values) in relation to their perceptions of luxury. U.S. consumers perceptions of luxury was not heavily weighed on by functional attributes but seemed to be an aspect of small percentage of participants in clusters 1 and 4 took into account. Notable differences between the U.S. and the German sample relate to the relative importance given to self gift-giving, extravagance and self-enrichment values by U.S. consumers. U.S. consumers purchased luxury as they perceived they would be happier if they owned status seeking luxury products. Additionally, luxury purchases among the U.S. consumers were more focused on rewarding themselves (individual reasons) rather than impress others (social reasons). U.S consumers felt that they were entitled to buy luxury which in turn helped them reduce their stress and feel good about themselves. On the other hand, German consumers in Wiedmann et al.'s (2009) study appreciated the exclusivity and workmanship of luxury products than the U.S. sample. Lastly, self-identity value was paramount among the U.S. consumers, however, among the German sample it had little relevance towards their perceptions of luxury.

The findings of this study have some similarities and differences with the Hennings et al.'s (2012) study that examined luxury value perceptions of consumers in ten countries including the U.S. It should be noted that Hennings et al. (2012) study used a shortened version of the LVP scale. Also, the age of U.S. participants in Hennings et al.'s (2012) study $\left(\mathrm{M}_{\mathrm{age}}=23.3\right.$ years $)$ was very young compared to this study $\left(\mathrm{M}_{\mathrm{age}}=35.76\right.$ years $)$ that could have attributed to different results. Notable similarities include that U.S. consumers in both these studies revealed that U.S. consumers did not relate aspects of financial and functional value of utmost importance in their perceptions of luxury. The second finding common to both these studies is the emphasis of "self", and the relative unimportance of others opinions in U.S. consumers luxury consumption decisions. Both the studies confirmed the role of uniqueness in U.S. consumers perceptions of luxury. Some aspects not directly evident in Hennings et al. (2012) study is the emphasis of self-enrichment, self gift-giving, self identity and self-directed pleasure of U.S. consumers. In the current study, U.S. consumers attributed higher importance to these values in their perceptions of luxury. Although, Hennings et al. (2012) study, identified that U.S. consumers in their study emphasize individual and social dimensions of luxury value, it is not clear which specific factors contributed to this understanding. This could be due to the use of a shortened version of the luxury value perception scale developed for their study. The other difference is the importance of functional value in the Hennings et al. (2012) study, which was not evident in the present study.

\section{Conclusion and Future Research Directions}

The global luxury marketplace is becoming highly competitive with consumers exposed to a variety of information from different channels. It thus becomes challenging for brands to keep up with the technological advancements and reach to the right consumer base. The purpose of this study was to understand value that U.S. consumers attached to luxury consumption after global recession. It included investigating both emotional and cognitive needs that are satisfied with luxury consumption. The findings support the factor structure proposed by Wiedmann et al. (2009) study and also provide a rigorously tested measuremet instrument for examining consumers luxury value perceptions. The findings of this study revealed that the largest cluster attached more importance to hedonic and usability aspects of luxury consumption. Knowing consumer's luxury value perceptions is helpful as they influence their luxury purchases. Therefore, understanding luxury value perceptions enhances the efficiency of marketing luxury brands (Wiedmann et al., 2009).

In marketing, consumer segmentation has always been considered a challenge (Dubois \& Duquesne, 1993). However, luxury brands were small companies (like Prada in 1978), often family owned, and their target consumer base was the upper-income class (Dubois \& Duquesne, 1993). Consequently, Dubois and Duquesne (1993) noted that luxury brands employed simple branding strategies (such as Vogue advertisements) and established shops in prime locations, like Fifth Avenue in New York. But the luxury market has grown immensely over the last decade (Ciornea et al., 2012; Wiedmann et al., 2009; Kurnaz, 2017), and evidently luxury products are more widely available to consumers than ever before (Kapferer \& Bastien, 2012). Furthermore, the global luxury industry is going through two interesting trends from: a) physical product to digital experiential and b) standardization to personalization (Deloitte, 2017). In other words, luxury brands today are global business empires in need of brand strategies to position themselves to different consumer segments. The findings of this study provide important insights about luxury value perceptions of U.S. consumers. 
There are some limitations that need to be noted. The sample in this study was recruited online through Amazon Mechanical Turk limiting participants who had internet access. The sample size in this study could limit the generalizability of the findings in the U.S. context. Future research with larger sample can further confirm the findings to increase the validity of the LVP model. This study can be replicated in the context of emerging economies as market trends show high growth potential for luxury industry in the countries like China, India, Mexico and Middle Eastern countries. Most of these countries have been identified as collectivistic societies with very high economic activity. Understanding of value perceptions of luxury consumers in these countries can provide important insights to luxury brand strategists.

\section{Managerial Implications}

One of the main contributions of this study was the theoretical justification of the LVP model by confirming its factor structure as proposed in Wiedmann et al.'s $(2007,2009)$ studies. The findings of this study provided empirical support for the latent luxury value construct influenced by individual, social, and functional luxury value perceptions in the U.S. context. The LVP model helped understanding the U.S. luxury consumers value perceptions from individual, social, and functional dimensions. This knowledge is important for marketers operating in dynamic market conditions (e.g. U.S.), as awareness of what consumers value in their luxury purchases may be helpful for them to develop targeted marketing communications. In the current study, the LVP model helped identify luxury value drivers of U.S. consumers and cluster them in homogenous segments. These findings may potentially help U.S. luxury brand marketers to know the needs and values of different customer segments, ultimately helping them to develop effective brand positioning strategies in a competitive marketplace.

The LVP model provides a broader view of consumers' perceptions regarding luxury consumption to include both emotional and cognitive elements (Wiedmann et al. 2009). Understanding what luxury consumers value the most in their purchases would help luxury brands to address psychological and emotional needs that U.S. consumers attach to luxury consumption. In a dynamic marketplace, consumers expect brands to understand what they need and value the most. The ability of brands to effectively respond to consumer needs is informed by their understanding of what luxury consumers value most in their purchases. The current study contributes to this understanding by identifying that U.S. consumers value individual aspects of luxury value (e.g. life enrichment, self identity) the most. The importance that this consumer base holds towards self can help marketers to customize product and service offerings.

Cluster analysis results from this study provide information of different U.S. luxury consumer segments that may help brands to understand consumer preferences of different demographics or psychographics. Recently, there has been shift among the U.S. consumer specifically towards a more individualistic attitude (Wike, 2016), that is also evident in the findings of the current study. Consumers are increasingly exposed to brand communications from different marketing channels. It is important that marketers do not focus communications only for one segment, but diversify their advertsing strategies to reach out wider consumer base. The findings of this study suggest that there is a need for brands to develop an integrated marketing communication with different brand positioning messages to satisfy the different values that consumers attach with luxury consumption.

Managerial implications based on the findings of this study include suggestions for brand marketers and strategiests. In this study, functional materialists, valued quality and had high ratings for materialistic value in their perceptions of luxury. Therefore, marketers need to emphasize the functional attributes of luxury products along with the happiness that the luxury purchase may give them. Furthermore, motivating this segment to purchase luxury products by highlighting high quality of the product may be more effective than the prestige value that it may entail. The largest cluster in this study, self-seeking hedonists valued hedonic and prestige aspects of luxury consumption. Furthermore, the consumers in this segment, perceived higher quality of life and valued the experience involved in their luxury consumption. Marketers thus can emphasize the individual and social components of luxury in their marketing communications. Luxury brands are increasingly connecting with their consumers through social media. Devloping personalized messaging and providing customized services may thus increase sales and brand loyalty. Marketing managers need to ensure that their advertising strategies should include images that portray extravagance, status and prestige. Rational functionalists in this study valued uniqueness in their luxury purchases. Portraying their unique self-identity through luxury consumption was paramount to consumers in this segment. Thus, luxury brand advertising strategies should include exclusivity, strong individualistic elements and aspired lifestyle. Introverted hedonists perceived luxury through the lens of functional attributes and personal pleasure felt in luxury consumption. Promotional messages thus may include information that emphasize functional benefits of luxury products. This segment did not perceive social aspects of luxury consumption and thus it is imperative to understand that motivating factors for this segment was largely focused on happiness one felt in owning unique luxury products and the emphasis on quality. 


\section{References}

Belk, R. W. (1985). Materialism: Trait aspects of living in the material world. Journal of Consumer Research, 12(3), 265-280. https://doi.org/10.1086/208515

Bourdieu, P. (1986). The force of law: Toward a sociology of the juridical field. Hastings LJ, 38, 805.

Buhrmester, M., Kwang, T., \& Gosling, S. D. (2011). Amazon's Mechanical Turk: A new source of inexpensive, yet high-quality, data?. Perspectives on Psychological Science, 6(1), 3-5. https://doi.org/10.1177/1745691610393980

Ciornea, R., Pop, M. D., Bacila, M. F., \& Drule, A. M. (2012). Was luxury little researched? An Exploration of studies and research trends in the area of marketing of luxury goods, before 2005. Management \& Marketing Journal, 10(2), 325-340.

Csaba, F. F. (2008). Redefining luxury: A review essay. Creative Encounters, 15, 1-32.

Danzinger, P. N. (2017, June). Luxury market growth in 2017? Keep your expectations low. Forbes. Retrived from

https://www.forbes.com/sites/pamdanziger/2017/06/05/luxury-market-growth-in-2017-keep-your-expectatio ns-low/\#b1f7f5538b83

Deloitte. (2017). Global Powers of Luxury Goods. Retrieved from https://www2.deloitte.com/content/dam/Deloitte/global/Documents/consumer-industrial-products/gx-cip-gl obal-powers-luxury-2017.pdf

Dubois, B., \& Duquesne, P. (1993). The market for luxury goods: Income versus culture. European Journal of Marketing, 27(1), 35-44. https://doi.org/10.1108/03090569310024530

Dubois, B., \& Laurent, G. (1994). Attitudes towards the concept of luxury: An exploratory analysis. ACR Asia-Pacific Advances.

Dubois, B., Laurent, G., \& Czellar, S. (2001). Consumer rapport to luxury: Analyzing complex and ambivalent attitudes (Vol. 736). Jouy-en-Josas: Groupe HEC.

Franke, N., \& Schreier, M. (2008). Product uniqueness as a driver of customer utility in mass customization. Marketing Letters, 19(2), 93-107. https://doi.org/10.1007/s11002-007-9029-7

George, D., \& Mallery, P. (2007). Discriminant analysis. IBM SPSS Statistics, 23.

Griskevicius, V., Tybur, J. M., Sundie, J. M., Cialdini, R. B., Miller, G. F., \& Kenrick, D. T. (2007). Blatant benevolence and conspicuous consumption: When romantic motives elicit strategic costly signals. Journal of Personality and Social Psychology, 93(1), 85-102. https://doi.org/10.1037/0022-3514.93.1.85

Groth, J. C., \& McDaniel, S. W. (1993). The exclusive value principle: The basis for prestige racing. Journal of Consumer Marketing, 10(1), 10-16. https://doi.org/10.1108/07363769310026539

Han, Y. J., Nunes, J. C., \& Drèze, X. (2010). Signaling status with luxury goods: The role of brand prominence. Journal of Marketing, 74(4), 15-30. https://doi.org/10.1509/jmkg.74.4.15

Hennigs, N., Wiedmann, K. P., Klarmann, C., Strehlau, S., Godey, B., Pederzoli, D., ... \& Oh, H. (2012). What is the value of luxury? A cross-cultural consumer perspective. Psychology \& Marketing, 29(12), 1018-1034. https://doi.org/10.1002/mar.20583

Hirschman, E. C., \& Holbrook, M. B. (1982). Hedonic consumption: emerging concepts, methods and propositions. The Journal of Marketing, 92-101. https://doi.org/10.2307/1251707

Horiuchi, Y. (1984). A systems anomaly: Consumer decision-making process for luxury goods (marketing, system science, behavior) (Doctoral dissertation).

Hu, L. T., \& Bentler, P. M. (1999). Cutoff criteria for fit indexes in covariance structure analysis: Conventional criteria versus new alternatives. Structural Equation Modeling: A Multidisciplinary Journal, 6(1), 1-55. https://doi.org/10.1080/10705519909540118

Hudders, L., \& Pandelaere, M. (2012). The silver lining of materialism: The impact of luxury consumption on subjective well-being. Journal of Happiness Studies, 13(3), 411-437. https://doi.org/10.1007/s10902-011-9271-9

Kalyoncuoglu, S., \& Sahin, B. (2017). Moderating Role of Materialism in the Effect of Perceived Value on Purchase Intention of Counterfeits of Luxury Brands. International Journal of Marketing Studies, 9(4), 76. 
Kapferer, J. N., \& Bastien, V. (2008). Luxe oblige (No. hal-00786816).

Kapferer, J. N., \& Bastien, V. (2012). The luxury strategy: Break the rules of marketing to build luxury brands. Kogan page publishers.

Kardes, F. R., Posavac, S. S., Cronley, M. L., \& Herr, P. (2008). Consumer inference.

Kurnaz, A. (2017). Examination of the Relationship between Luxury Value Perception and Shopping Motivations: Turkey Sample. International Journal of Marketing Studies, 9(5), 108. https://doi.org/10.5539/ijms.v9n5p108

Lee, J. H., \& Hwang, J. (2011). Luxury marketing: The influences of psychological and demographic characteristics on attitudes toward luxury restaurants. International Journal of Hospitality Management, 30(3), 658-669. https://doi.org/10.1016/j.jhhm.2010.12.001

Lim, W. M., Ting, D. H., Khoo, P. T., \& Wong, W. Y. (2012). Understanding consumer values and socialization-A case of luxury products. Management \& Marketing, 7(2), 209.

Liu, F., Li, J., Mizerski, D., \& Soh, H. (2012). Self-congruity, brand attitude, and brand loyalty: A study on luxury brands. European Journal of Marketing, 46(7/8), 922-937. https://doi.org/10.1108/03090561211230098

Macdonald, E. K., \& Sharp, B. M. (2000). Brand awareness effects on consumer decision making for a common, repeat purchase product: A replication. Journal of Business Research, 48(1), 5-15. https://doi.org/10.1016/S0148-2963(98)00070-8

Mason Roger, S. (1981). Conspicuous Consumption. Gower, Farnborough.

Nelissen, R. M., \& Meijers, M. H. (2011). Social benefits of luxury brands as costly signals of wealth and status. Evolution and Human Behavior, 32(5), 343-355. https://doi.org/10.1016/j.evolhumbehav.2010.12.002

Reyneke, M., Pitt, L., \& Berthon, P. R. (2011). Luxury wine brand visibility in social media: An exploratory study. International Journal of Wine Business Research, 23(1), 21-35. https://doi.org/10.1108/17511061111121380

Richins, M. L., \& Dawson, S. (1992). A consumer values orientation for materialism and its measurement: Scale development and validation. Journal of Consumer Research, 19(3), 303-316. https://doi.org/10.1086/209304

Roberts, F. (2017, July). Inside the \$85billion US luxury good market: Slow growth, but still leading the pack. Luxury Society. Retreived from https://www.luxurysociety.com/en/articles/2017/07/us-luxury-goods-market-sees-another-year-slow-growth

Shukla, P., \& Purani, K. (2012). Comparing the importance of luxury value perceptions in cross-national contexts. Journal of Business Research, 65(10), 1417-1424. https://doi.org/10.1016/j.jbusres.2011.10.007

Thomas, T. (2008). Questionable Luxury Taxes: Results from a Mating Game (No. 86). Diskussionspapier//Helmut-Schmidt-Universit\%o t Universit\%o t der Bundeswehr Hamburg, F\%o chergruppe Volkswirtschaftslehre.

Thompson, B. (2004). Exploratory and confirmatory factor analysis: Understanding concepts and applications. Washington, DC: American Psychological Association. https://doi.org/10.1037/10694-000

Tian, K. T., Bearden, W. O., \& Hunter, G. L. (2001). Consumers' need for uniqueness: Scale development and validation. Journal of Consumer Research, 28(1), 50-66. https://doi.org/10.1086/321947

Tsiotsou, R. (2006). The role of perceived product quality and overall satisfaction on purchase intentions. $\begin{array}{llllll}\text { International Journal of Consumer } & \text { Studies, } & 30(2), & \text { 207-217. }\end{array}$ https://doi.org/10.1111/j.1470-6431.2005.00477.x

Tynan, C., McKechnie, S., \& Chhuon, C. (2010). Co-creating value for luxury brands. Journal of Business Research, 63(11), 1156-1163. https://doi.org/10.1016/j.jbusres.2009.10.012

Vigneron, F., \& Johnson, L. W. (1999). A review and a conceptual framework of prestige-seeking consumer behavior. Academy of Marketing Science Review.

Vigneron, F., \& Johnson, L. W. (2004). Measuring perceptions of brand luxury. Journal of Brand Management, 11, 484-506. https://doi.org/10.1057/palgrave.bm.2540194

Wiedmann, K. P., Hennigs, N., \& Siebels, A. (2007). Understanding and measuring luxury value: a 
multidimensional model of consumers' luxury perception. Marketing Theory and Applications, 393.

Wiedmann, K. P., Hennigs, N., \& Siebels, A. (2009). Value-based segmentation of luxury consumption behavior. Psychology \& Marketing, 26(7), 625-651. https://doi.org/10.1002/mar.20292

Wike, R. (2016). 5 ways Americans and Europeans are different. Retrieved from http://www.pewresearch.org/fact-tank/2016/04/19/5-ways-americans-and-europeans-are-different/

Wilcox, K., Kim, H. M., \& Sen, S. (2009). Why do consumers buy counterfeit luxury brands?. Journal of Marketing Research, 46(2), 247-259. https://doi.org/10.1509/jmkr.46.2.247

\section{Copyrights}

Copyright for this article is retained by the author, with first publication rights granted to the journal.

This is an open-access article distributed under the terms and conditions of the Creative Commons Attribution license (http://creativecommons.org/licenses/by/4.0/). 